\title{
Teores de proteínas e lipídeos de Chlorella sp. cultivada em concentrado de dessalinização residual
}

\author{
Protein and lipid contents from Chlorella sp. Cultivated in residual concentrated desalination
}

\author{
Ângelo Paggi Matos $^{I^{*}}$ Luiz Rodrigo Ito Morioka ${ }^{\mathrm{I}}$ Ernani Sebastião Sant'Anna ${ }^{\mathrm{I}}$ \\ Kepler Borges França ${ }^{I I}$
}

\section{RESUMO}

A dessalinização é um método de obtenção de água potável limitado pelos problemas ambientais, causados pelo resíduo gerado em seu processo. $O$ objetivo deste estudo foi avaliar o cultivo de Chlorella sp., em meio de cultura a base de concentrado de dessalinização, e determinar os teores de proteínas e lipídeos ao longo dos ciclos de cultivo. Os cultivos foram desenvolvidos em fotobiorreatores cônicos invertidos (4L) e mantidos durante 28 dias resultando em quatro ciclos de cultivo. Para cada ciclo de cultivo, os valores de biomassa (peso seco, $g$ $\left.L^{-1}\right)$ resultaram em $1^{o}$ ciclo, 1,$55 ; 2^{\circ}$ ciclo, 0,$96 ; 3^{\circ}$ ciclo, 0,62 , e $4^{\circ}$ ciclo em 0,42 . Os teores de proteinas e lipídeos variaram entre 45,2 a 48,8\% e 8,5 a 11,4\%, respectivamente. O primeiro ciclo de cultivo apresentou a maior produtividade em biomassa $\left(P_{B}=200\right.$ $m g L^{-1}$ dia $\left.a^{-1}\right)$ e produtividade lipídica $\left(P_{L}=19,6 \mathrm{mg} \mathrm{L}^{-1}\right.$ dia $\left.^{-1}\right)$, bem como o maior teor de proteinas $(48,8 \%)$. O maior teor de lipídeos $(11,4 \%)$ foi obtido no segundo ciclo de cultivo. Foi observado, nos quatro ciclos de cultivo, que a produtividade em biomassa está diretamente correlacionada com a produtividade lipídica, indicando que quanto maior a $P_{B}$ maior será a $P_{L}$. Os resultados da cultura de Chlorella $s p$. demonstraram que é possivel utilizar o concentrado de dessalinização residual como meio de cultura alternativo e obter biomassa ao longo de quatro ciclos de cultivo, sem comprometer os teores de proteínas e lipideos na célula microalgal.

Palavras-chave: águas residuais, biomassa, microalga.

\section{ABSTRACT}

Desalination process is a method of obtaining potable drinking water which is limited by environmental problems caused by the waste generated in the process. The aim of this study was to evaluate the cultivation of Chlorella sp. in a culture medium based on residual concentrated desalination and determines the protein and lipid contents along the cultivation cycles. The cultures were developed in a reverse conical photobioreactors (4L) during 28 days resulting in four cultivation cycles. For each cultivation cycle, the value of biomass (dry weight $g L^{-1}$ ) resulted: $1^{\text {st }}$ cycle, 1.55 g; $2^{\text {nd }}$ cycle, 0.96; $3^{\text {rd }}$ cycle, 0.62 and $4^{\text {th }}$ cycle, 0.42 . The protein and lipid levels ranged from 45.2 to $48.8 \%$ and 8.5 to $11.4 \%$, respectively. The first cultivation cycle showed the highest biomass productivity $\left(P_{B}=200 \mathrm{mg} \mathrm{L}^{-1}\right.$ dia $\left.{ }^{-1}\right)$ and lipid productivity $\left(P_{L}=19.6\right.$ $m g L^{-1}$ dia $^{-1}$ ), as well as the highest protein content (48.8\%). The highest lipid content (11.4\%) was observed on second cultivation cycle. It was observed during the four cultivation cycles that the biomass productivity is directly correlated to lipid productivity, indicating that higher $P_{B}$ higher will be $P_{L}$. The results from this study showed that it is possible to growth Chlorella sp. in a culture medium based on residual concentrated desalination for biomass production along the four cultivation cycles and also, without compromise the protein and lipid contents into the microalgal cell.

Key words: biomass, microalga, wastewaters.

\section{INTRODUÇÃO}

Um número crescente de equipamentos de dessalinização de água por osmose reversa tem sido instalado na região semiárida brasileira. Devido à qualidade química muitas vezes não favorável, ou seja, teores de cloretos acima de $1.000 \mathrm{mg} \mathrm{L}^{-1}$, característica esta que as torna impróprias ao consumo humano, estas águas necessitam ser dessalinizadas (SUASSUNA, 2005). No entanto, o processo de dessalinização por osmose reversa gera um efluente, que quase na totalidade dos casos, estes efluentes não

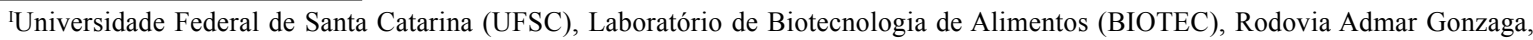
1346, Itacorubi, 88034-001, Florianópolis, SC, Brasil. E-mail: angelosotam@gmail.com. *Autor para correspondência.

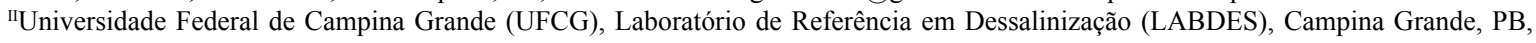
Brasil.
} 
recebem nenhum tipo de tratamento e são lançados diretamente no solo, propiciando acúmulo de sais nas camadas superficiais, os quais podem ser lixiviados com as águas das chuvas, atingindo os aquíferos e causando salinização, sodicidade e eritrofização do solo (MENEZES et al., 2011).

Devido ao potencial impacto ambiental que pode ser gerado pelo descarte inadequado dos subprodutos ou efluentes de dessalinização, algumas alternativas têm sido sugeridas para o reuso deste efluente, tais como: no cultivo de peixes (Oreochromis niloticus) em tanques revestidos por geomembranas, na larvicultura (Panaeus vannamei) e na irrigação de plantas halófitas, Atriplex nummularia - utilizada como recurso forrageiro. Estas ações visam à reciclagem do concentrado salino com a finalidade de produção de alimentos e nutrição animal (PORTO et al., 2006). É geralmente reconhecido que as microalgas desempenham um papel importante na auto-purificação de águas residuais (PITTMAN et al., 2011). Ainda, a biotecnologia de microalgas demonstra ser versátil, podem ser cultivadas em diferentes meios de cultura e substratos, atuar em processos de tratamento de efluentes, biorremoção de metais pesados, e gerar produtos biotecnológicos para a indústria de ração animal, fertilizantes e química fina (PEREZ-GARCIA et al., 2011). Desta maneira, o cultivo de microalgas em concentrado de dessalinização é uma forma eficiente de remoção de nutrientes. As microalgas assimilam os nutrientes existentes no concentrado incorporando-os à sua biomassa, obtendo um produto nutricionalmente rico, que pode ser utilizado como suplemento alimentar, na aquicultura e em outras áreas de atuação (MORIOKA et al. 2014). Desta maneira, o objetivo deste estudo foi avaliar os teores de proteínas e lipídeos de Chlorella sp. ao longo dos ciclos de cultivo em um meio de cultivo contendo concentrado de dessalinização residual.

\section{MATERIAL E MÉTODOS}

Amostras do concentrado de dessalinização foram coletadas em uma planta de dessalinização de água salobra, localizada no município de São João do Cariri, Paraíba. As amostras foram armazenadas em recipientes plásticos de 100 litros em câmara de refrigeração a $-20^{\circ} \mathrm{C}$ no Laboratório de Biotecnologia de Alimentos (BIOTEC) da Universidade Federal de Santa Catarina (UFSC). Características físico-químicas do concentrado de dessalinização (Tabela 1) foram determinadas de acordo com a metodologia descrita por Standard Methods for the Examination of Water and Wastewater - APHA (1998).
Tabela 1 - Características do concentrado de dessalinização.

\begin{tabular}{ll}
\hline Parâmetro & Valores \\
\hline $\mathrm{Cl}\left(\mathrm{mg} \mathrm{L}^{-1}\right)$ & $1.691,3$ \\
$\mathrm{Ca}\left(\mathrm{mg} \mathrm{L}^{-1}\right)$ & 126,5 \\
$\mathrm{Fe}\left(\mathrm{mg} \mathrm{L}^{-1}\right)$ & 0,13 \\
$\mathrm{~K}\left(\mathrm{mg} \mathrm{L}^{-1}\right)$ & 47,0 \\
$\mathrm{Mg}\left(\mathrm{mg} \mathrm{L}^{-1}\right)$ & 4,74 \\
$\mathrm{Na}\left(\mathrm{mg} \mathrm{L}^{-1}\right)$ & 987,5 \\
$\mathrm{NH}_{4}^{+}\left(\mathrm{mg} \mathrm{L}^{-1}\right)$ & 1,35 \\
Sulfatos $\left(\mathrm{mg} \mathrm{L}^{-1}\right)$ & 138,0 \\
Fósforos totais $\left(\mathrm{mg} \mathrm{PO}_{4}{ }^{3-} \mathrm{P} \mathrm{L} \mathrm{L}^{-1}\right)$ & 0,70 \\
Dureza total $\left(\mathrm{CaCO}_{3}, \mathrm{mg} \mathrm{L}^{-1}\right)$ & 985,2 \\
$\mathrm{TDS}\left(\mathrm{mg} \mathrm{L}^{-1}\right)$ & $2.190,5$ \\
$\mathrm{Nitrogênio} \mathrm{total}\left(\mathrm{mg} \mathrm{N} \mathrm{L}^{-1}\right)$ & 30,0 \\
Condutividade $\left(\mu \mathrm{Sm}^{-1}\right)$ & $4.875,0$ \\
pH & 8.11 \\
\hline
\end{tabular}

Nota: TDS significa Sólidos Totais Dissolvidos.

Uma cepa selvagem, chamada TU1, foi obtida em tanques de cultivo de peixes contendo concentrado de dessalinização em São João do Cariri, Paraíba. A estirpe foi purificada em meio de cultura Bold Basal Medium (BBM) solidificado com ágar a $1,5 \%$. A estirpe (TU1) adaptou-se no meio BBM e foi identificada morfologicamente como espécie Chlorella, renomeada como Chlorella sp. A microalga foi mantida em BBM modificado (CONNON, 2007) contendo os seguintes componentes: $0.075 \mathrm{~g} \mathrm{~L}^{-1} \mathrm{~K}_{2} \mathrm{HPO}_{4}, 0.014 \mathrm{~g} \mathrm{~L}^{-1}$ $\mathrm{KH}_{2} \mathrm{PO}_{4}, 0.075 \mathrm{~g} \mathrm{~L}^{-1} \mathrm{MgSO}_{4} 7 \mathrm{H}_{2} \mathrm{O}, 0.09 \mathrm{~g} \mathrm{~L}^{-1} \mathrm{NaNO}_{3}$, $0.025 \mathrm{~g} \mathrm{~L}^{-1} \mathrm{CaCl}_{3} 2 \mathrm{H}_{2} \mathrm{O}, 0.025 \mathrm{~g} \mathrm{~L}^{-1} \mathrm{NaCl}, 0.05 \mathrm{~g}$ $\mathrm{L}^{-1}$ EDTA-Na $4,0.00498 \mathrm{~g} \mathrm{~L}^{-1} \mathrm{FeSO}_{4} 7 \mathrm{H}_{2} \mathrm{O}, 0.01142$ $\mathrm{g} \mathrm{L} \mathrm{L}^{-1} \mathrm{H}_{3} \mathrm{BO}_{3}, 0.232 \mathrm{mg} \mathrm{L} \mathrm{MnCl}_{2} .4 \mathrm{H}_{2} \mathrm{O}, 1.41 \mathrm{mg}$ $\mathrm{L}^{-1} \mathrm{ZnSO}_{4} .7 \mathrm{H}_{2} \mathrm{O}, 0.252 \mathrm{mg} \mathrm{L}^{-1} \mathrm{CuSO}_{4} .5 \mathrm{H}_{2} \mathrm{O}, 0.192$ $\mathrm{mg} \mathrm{L}^{-1} \mathrm{NaMoO}_{4} .5 \mathrm{H}_{2} \mathrm{O}, 0.080 \mathrm{mg} \mathrm{L}{ }^{-1} \mathrm{CoCl}_{2} \cdot 6 \mathrm{H}_{2} \mathrm{O}$, $10 \mathrm{~g} \mathrm{~L}^{-1}$ de extrato de levedura e $250 \mathrm{~mL} \mathrm{~L}^{-1} \mathrm{de}$ concentrado de dessalinização.

$\mathrm{O}$ crescimento da microalga até a fase exponencial $\left(2,5 \times 10^{6}\right.$ células $\left.\mathrm{mL}^{-1}\right)$ serviu como inóculo, que foi transferido em um volume correspondente a $10 \%(\mathrm{v} / \mathrm{v})$ para biorreatores cônicos invertidos com capacidade de 4,0L (Figura 1), contendo $3,5 \mathrm{~L}$ de solução BBM modificado, realizados em três repetições independentes. $\mathrm{O}$ cultivo foi mantido sob aeração constante fornecido por compressão do ar atmosférico saturado, temperatura de $27^{\circ} \mathrm{C}$ $\pm 2^{\circ} \mathrm{C}$, iluminação contínua de $150 \mu \mathrm{mol} \mathrm{m} \mathrm{m}^{-2} \mathrm{~s}^{-1}$, aproximadamente 10 klux, provenientes de lâmpadas fluorescentes de $40 \mathrm{~W}$, com fotoperíodo de 12-h claro/12-h escuro. 


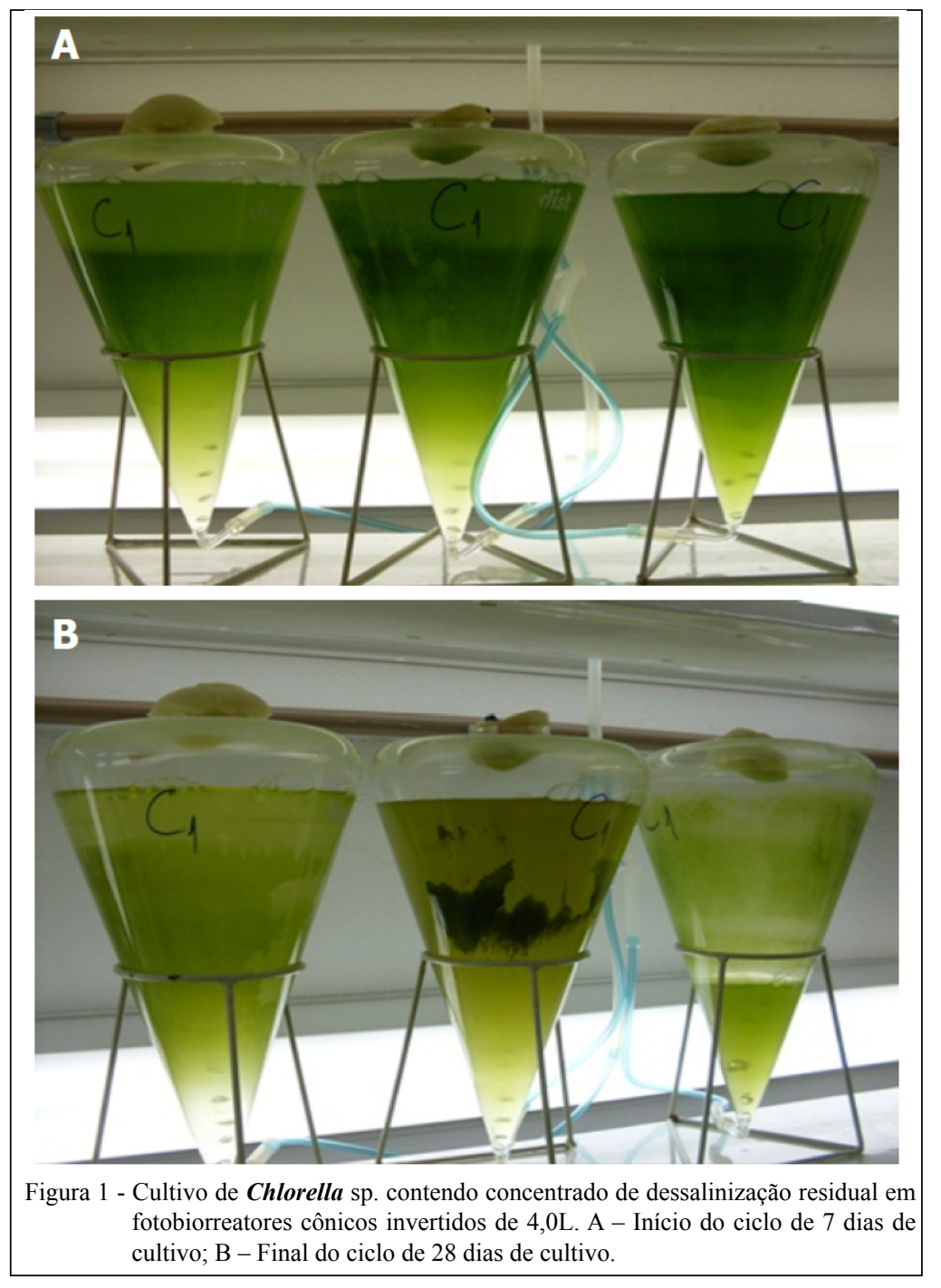

Para cada ciclo de cultivo, do volume total contido em cada biorreator $(3.500 \mathrm{~mL}), 3.000$ $\mathrm{mL}$ foram centrifugados em centrífuga refrigerada (Nova Técnica, São Paulo, Brasil). Após a separação da biomassa por meio da centrifugação, o sobrenadante (aproximadamente $3.000 \mathrm{~mL}$ ) contendo o meio de cultivo residual parcialmente exaurido, foi reintroduzido nos fotobiorreatores e recomposto quimicamente com a adição de $10 \mathrm{~mL} \mathrm{~L}^{-1}$ de nitrato de sódio (concentração de $0,09 \mathrm{~g} \mathrm{~L}^{-1}$ ). A biomassa foi lavada duas vezes com água destilada $(300 \mathrm{~mL})$ para retirada do sal absorvido às células e após secagem a $60^{\circ} \mathrm{C}$ por 12 horas, foram analisados os teores de proteínas e lipídeos totais para cada ciclo de sete dias de cultivo. Para determinação do peso seco, foram filtrados $30 \mathrm{~mL}$ da cultura em filtro de acetato de celulose com diâmetro de poros de $0,45 \mu \mathrm{m}$ (Sartorius Stedim Biotech, Gottingen, Alemanha). O papel com as células permaneceram em estufa a $105^{\circ} \mathrm{C}$ por 24 horas, até peso constante.

Para a determinação de lipídeos totais, foram pesados 5,0 $\mathrm{g}$ da amostra e transferido para o cartucho de extração em aparelho de Soxhlet com $n$-hexano como solvente de extração, durante um período de 4 a 8 horas. A temperatura foi mantida constante no aparelho extrator, dentro da faixa de ebulição do $n$-hexano (68$70{ }^{\circ} \mathrm{C}$ ). Balões de $250 \mathrm{~mL}$ foram utilizados no aparato e o volume de solvente usado para cada extração foi de aproximadamente $170 \mathrm{~mL}$. Após o término do período de extração e arrefecimento da miscela, foram retiradas alíquotas de 3,0 mL para análises de lipídios totais (AOAC, 2005).

O teor protéico total na biomassa seca foi determinado pelo método de Kjedahl, adotando-se o fator de 6,25 para conversão a partir dos teores de nitrogênio total (AOAC, 2005). As 
amostras desengorduradas, provenientes da etapa de lipídeos, foram trituradas novamente e submetidas a aquecimento intenso, na presença de $\mathrm{H}_{2} \mathrm{SO}_{4}$ concentrado e catalisador. Tal procedimento promove a destruição da matéria orgânica e formação de nitrogênio inorgânico, na forma de $\left(\mathrm{NH}_{4}\right)_{2} \mathrm{SO}_{4}$. A alcalinização deste resíduo, durante uma etapa de destilação do nitrogênio, promove a conversão do sal em amônia, recolhida em solução saturada de $\mathrm{HBO}_{3}$. A titulação desta solução com $\mathrm{HCl} 0,20 \mathrm{~N}$ permite a determinação da concentração de nitrogênio da amostra utilizada.

A produtividade em biomassa $\left(\mathrm{P}_{\mathrm{B}}\right)$ e produtividade lipídica $\left(\mathrm{P}_{\mathrm{L}}\right)$ foram calculadas de acordo as equações (1) e (2) descrita por DICKINSON et al. (2013).

$$
\mathrm{P}_{\mathrm{B}}=\frac{\mathrm{X}_{\mathrm{m}}-\mathrm{X}_{0}}{\mathrm{t}_{\mathrm{f}}}
$$

Prod. Lipídica (mg Lip. $\left.\mathrm{L}^{-1} \mathrm{dia}^{-1}\right)=\mathrm{P}_{\mathrm{B}} \mathrm{x}$ lipídio/biomassa (p/p)

Onde $\mathrm{X}_{\mathrm{m}}$ representa a concentração de biomassa no final do ciclo de cultivo, $\mathrm{X}_{0}$ representa a concentração de biomassa no início do cultivo e $\mathrm{t}_{\mathrm{f}} \mathrm{o}$ tempo final do ciclo de cultivo.

Os resultados de concentração final de biomassa, teores de proteínas e lipídeos totais da microalga Chlorella sp. foram analisados por meio de Análise de Variância (ANOVA) e as médias comparadas pelo Teste de Tukey com nível de significância de 5\%.

\section{RESULTADOS E DISCUSSÃO}

Pode-se observar nas tabelas 2 e 3 os resultados obtidos da biomassa, teores de proteínas e lipídeos, bem como, a produtividade em biomassa $\left(\mathrm{P}_{\mathrm{B}}\right)$ e produtividade lipídica $\left(\mathrm{P}_{\mathrm{L}}\right)$ da microalga Chlorella sp. cultivada em meio de cultura à base de concentrado de dessalinização residual ao longo de quatro ciclos de cultivo.

Foi possível cultivar a microalga no mesmo meio residual, por quatro ciclos consecutivos de cultivo. No quarto e último ciclo de cultivo houve uma diferenciação na coloração das culturas, a cor inicialmente verde, associada ao processo fotossintético e consequente produção de clorofila, tornou-se amarelado indicando fase de declínio (Figura 1). Provavelmente, devido à limitação de nutrientes e da intensidade luminosa limitada pelo efeito de sombreamento causado pela aderência das microalgas no interior dos fotobiorreatores (BEZERRA et al., 2012).

Ao se considerar a razão de N/P em organismos fitoplanctônicos de oceanos, REDFIELD (1958) assumiu que a média estequiométrica de N/P nestes micro-organismos era de $16 \mathrm{~N} / \mathrm{P}$. No entanto, em cultivos de algas em escala de laboratório, a razão de N/P pode variar amplamente desde 8,2 a 45,0 (KLAUSMEIER et al., 2004). Por outro lado, cultivo de microalgas em sistemas utilizando águas residuais, a razão de N/P pode variar entre 4/1 a 40/1, dependendo da espécie de alga e disponibilidade de nutrientes (PARK et al., 2011). Em nosso estudo, para que houvesse um crescimento microalgal satisfatório em água residual dessalinizada, foi necessário adicionar $10 \mathrm{~mL} \mathrm{~L}^{-1}$ de nitrato de sódio (concentração de $0,09 \mathrm{~g} \mathrm{~L}^{-1}$ ) após cada ciclo de cultivo e assim, estabelecer uma razão de 5,0 N/P (63,0 mg N/ 12,4 $\mathrm{mg} \mathrm{P})$. Adicionalmente, $\mathrm{CO}_{2}$ atmosférico saturado foi introduzido continuamente nos cultivos, a fim de manter um crescimento adequado durante quatro ciclos de cultivo.

A ordem decrescente do acúmulo de biomassa, em $\mathrm{g} \mathrm{L}^{-1}$, foi de: 1,$55 ; 0,96 ; 0,62$ e 0,42 (Figura 2). A microalga não apresentou variações significativas $(\mathrm{P}<0,05)$ na composição química das proteínas e lipídeos totais (Tabela 2). O primeiro ciclo de cultivo exibiu o maior teor de proteínas $(46,8 \%)$, além da maior produtividade em biomassa $\left(\mathrm{P}_{\mathrm{B}}=200 \mathrm{mg} \mathrm{L}^{-1} \mathrm{dia}^{-1}\right)$ e produtividade lipídica $\left(\mathrm{P}_{\mathrm{L}}=19,6 \mathrm{mg} \mathrm{L}^{-1} \mathrm{dia}^{-1}\right)$ (Tabela 3). Os teores de lipídeos variam entre 8,5 a $11,4 \%$, sendo que o segundo ciclo de cultivo apresentou o maior teor de lipídeos $(11,4 \%)$. Na figura 3, é possível visualizar

Tabela 2 - Valores da biomassa em peso seco, proteínas e lipídeos totais de Chlorella sp. em cada ciclo de sete dias de cultivo.

\begin{tabular}{lccc}
\hline Ciclos de cultivo & Biomassa peso seco $\left(\mathrm{g} \mathrm{L}^{-1}\right)$ & Proteínas totais $(\%)$ & Lipídeos totais $(\%)$ \\
\hline $1^{\mathrm{o}}$ & $1,55 \pm 0,20^{\mathrm{a}}$ & $46,80^{\mathrm{a}}$ & $9,88^{\mathrm{a}}$ \\
$2^{\mathrm{o}}$ & $0,96 \pm 0,12^{\mathrm{b}}$ & $45,27^{\mathrm{a}}$ & $11,46^{\mathrm{a}}$ \\
$3^{\mathrm{o}}$ & $0,62 \pm 0,21^{\mathrm{c}}$ & $46,44^{\mathrm{a}}$ & $8,57^{\mathrm{a}}$ \\
$4^{\mathrm{o}}$ & $0,42 \pm 0,15^{\mathrm{d}}$ & $45,31^{\mathrm{a}}$ & $8,95^{\mathrm{a}}$ \\
\hline
\end{tabular}

Médias seguidas de letras minúsculas iguais na mesma coluna, não diferem pelo Teste de Tukey, ao nível de $5 \%$ de significância. 
Tabela 3 - Produtividade em biomassa e lipídica de Chlorella sp. em cada ciclo de sete dias de cultivo.

\begin{tabular}{lcr}
\hline Ciclos de cultivo & Produtividade biomassa $\left(\mathrm{P}_{\mathrm{B}}\right)\left(\mathrm{mg} \mathrm{L}^{-1} \operatorname{dia}^{-1}\right)$ & ${\text { Produtividade lipídica }\left(\mathrm{P}_{\mathrm{L}}\right)\left(\mathrm{mg} \mathrm{L}^{-1} \operatorname{dia}^{-1}\right)}_{19,6 \pm 2,1^{\mathrm{a}}}$ \\
\hline $1^{\mathrm{o}}$ & $200 \pm 0,22^{\mathrm{a}}$ & $13,6 \pm 1,4^{\mathrm{ab}}$ \\
$2^{\mathrm{o}}$ & $120 \pm 0,15^{\mathrm{ab}}$ & $5,9 \pm 2,1^{\mathrm{b}}$ \\
$3^{\mathrm{o}}$ & $70 \pm 0,26^{\mathrm{ab}}$ & $3,5 \pm 1,4^{\mathrm{b}}$ \\
$4^{\mathrm{o}}$ & $40 \pm 0,16^{\mathrm{b}}$ & \\
\hline
\end{tabular}

Médias seguidas de letras minúsculas iguais na mesma coluna, não diferem pelo Teste de Tukey, em nível de 5\% de significância.

a correlação da produtividade em biomassa (mg L $\mathrm{L}^{-1}$ $\left.\mathrm{dia}^{-1}\right)$ de Chlorella sp. com a produtividade lipídica $\left(\mathrm{mg} \mathrm{L}^{-1} \mathrm{dia}^{-1}\right)$ e teor de lipídeos (\%) em função dos ciclos de cultivo. Como pode ser visto na figura 3, a produtividade em biomassa é diretamente proporcional à produtividade lipídica, mas não necessariamente está correlacionada com o teor de lipídeos. Tais observações também foram reportadas por Griffiths et al. (2009) que enfatizaram que o teor de lipídeos obtidos em microalgas não está necessariamente correlacionado com a produtividade lipídica. De fato, neste estudo, o primeiro ciclo de cultivo resultou em maior $\mathrm{P}_{B}$ e $\mathrm{P}_{L}$, mas não resultou no maior teor de lipídeos, o qual foi observado em maior proporção no segundo ciclo de cultivo.

$\mathrm{O}$ alto teor de proteínas verificado nos quatro ciclos de cultivo (45,2-48,8\%) é evidente na célula microalgal. É de notar que a biomassa de Chlorella é considerada GRAS (Generally Recognized As Safe) pelo FDA (Food and Drug Administration) dos Estados Unidos, reconhecida como suplemento alimentar sem causar risco à saúde humana (COSTA et al., 2006). Assim, a microalga de Chlorella sp. pode ser cultivada em um meio de cultura alternativo, sem comprometer o teor de proteína na célula microalgal e ainda, reutilizar por quatro ciclos de cultivo o meio residual contendo concentrado de dessalinização.

\section{CONCLUSÃO}

Quatro foram os ciclos de cultivo da microalga Chlorella sp. utilizando o concentrado de dessalinização residual. O maior teor de biomassa 1,55 $\mathrm{g} \mathrm{L}^{-1}$ ocorreu no primeiro ciclo de cultivo até o decréscimo de $0,42 \mathrm{~g} \mathrm{~L}^{-1}$. Os teores de proteínas e lipídeos extraídos da biomassa variam entre 45,2$48,8 \%$ e $8,5-11,4 \%$, respectivamente. O primeiro ciclo de cultivo resultou na maior produtividade em biomassa e lipídica, 200 e $19 \mathrm{mg} \mathrm{L}^{-1} \mathrm{dia}^{-1}$, respectivamente. O cultivo de Chlorella sp. em concentrado de dessalinização representa uma opção atrativa para o desenvolvimento de complementos nutricionais e alimentação animal em virtude, do alto teor de proteínas.

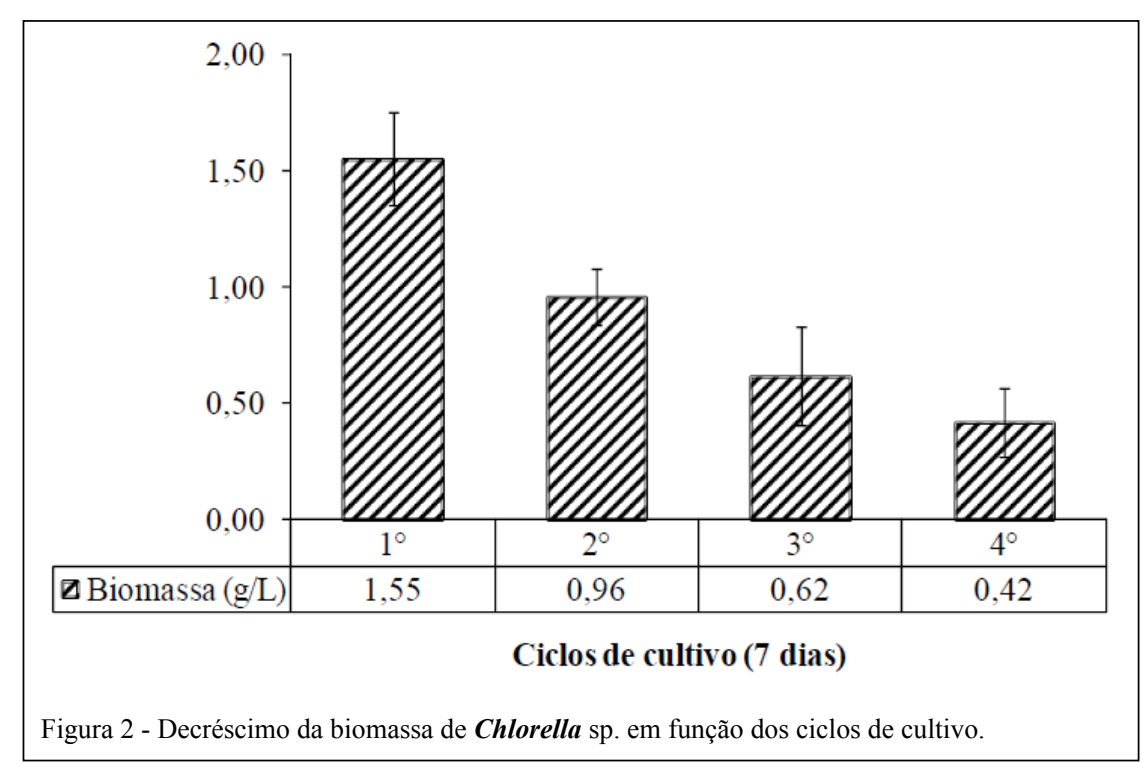

Ciência Rural, v.45, n.2, fev, 2015. 


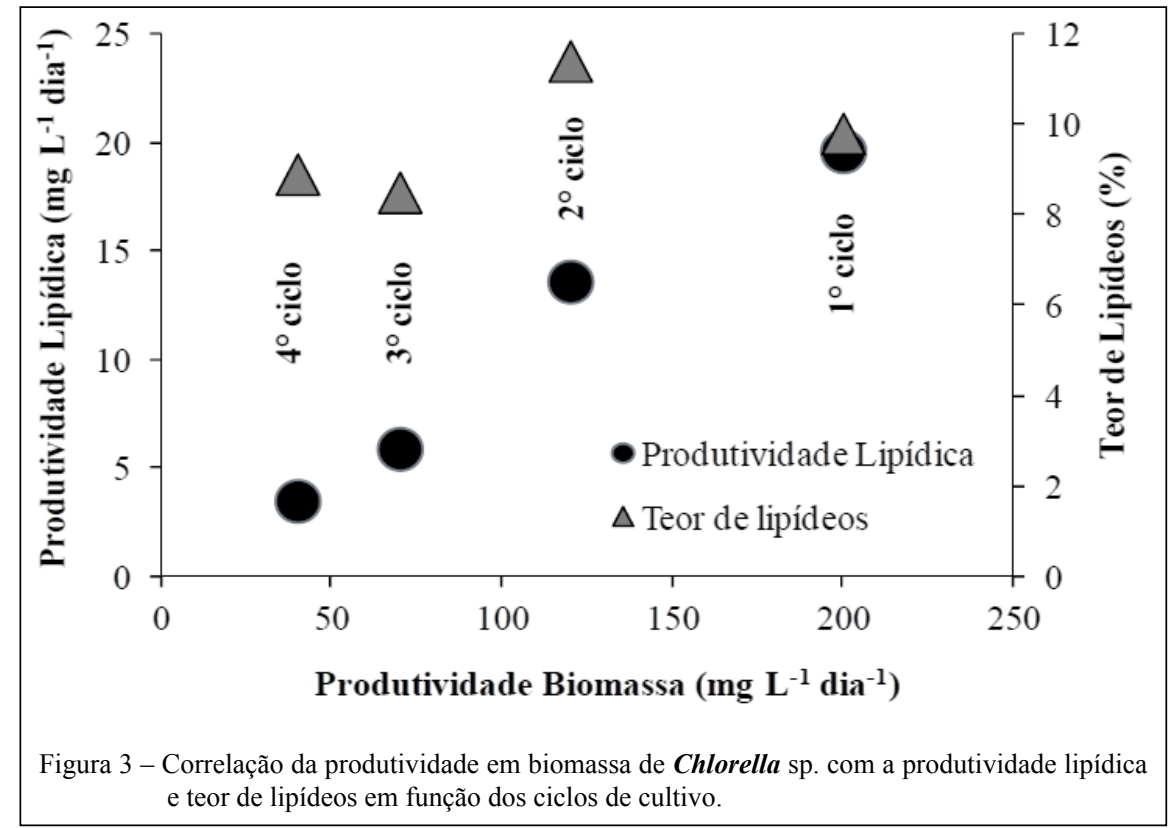

\section{AGRADECIMENTOS}

Os autores agradecem ao suporte financeiro do Conselho Nacional de Desenvolvimento Científico e Tecnológico (CNPq) (projeto $\left.\mathrm{n}^{\circ} 574.716 / 2008-4\right)$ e à CAPES, pela concessão da bolsa de estudos. Apreciamos as contribuições e sugestões dos revisores.

\section{REFERÊNCIAS}

AMERICAN PUBLIC HEALTH ASSOCIATION. Standard methods for the examination of water and wastewater. 20.ed. New York: APHA, 1998. 1368p.

ASSOCIATION OF OFFICIAL ANALYTICAL CHEMISTS (AOAC). Official methods of analysis of the Association of Official Analytical Chemists. 18.ed. Arlington, 2005. 1141p.

BEZERRA, R. P. et al. Effects of photobioreactor configuration, nitrogen source and light intensity on the fed-batch cultivation of Arthrospira (Spirulina) platensis. Bioenergetic aspects. Biomass and Bioenergy, v. 37, p. 309-317, 2012. Disponível em: <http:// www.sciencedirect.com/science/article/pii/S0961953411005952>. Acesso em: 11 ago. 2012. DOI: 10.1016/j.biombioe.2011.11.007.

CONNON, R. Culturing of Chlorella vulgaris - Standard Operating Procedure, SOP on how to prepare Bold's Basal Medium (BBM), 2007. University of Reading. Disponível em: $<$ http://www.biosci.rdg.ac.uk/Research/eb/daphnia.htm>. Acesso em: 28 mai. 2012.

COSTA, J. A. V. et al. Perfil de ácidos graxos das microalgas Chlorella vulgaris e Chlorella minutissima cultivadas em diferentes condições. Alimentos e Nutrição, v. 17, n.4, p.429-436, 2006. Disponível em: <http://serv-bib.fcfar.unesp.br/seer/index. php/alimentos/article/viewFile/300/291>.

Acessado em: 10 jul. 2012.

DICKINSON, K. E. et al. Nutrient remediation rates in municipal wastewater and their effect on biochemical composition of the microalga Scenedesmus sp. AMDD. Algal Research, v. 2, p. 127-134, 2013. Disponível em: <http://www.sciencedirect.com/ science/article/pii/S221192641300026X > . Acessado em: 15 nov. 2013. DOI: $10.1016 /$ j.algal.2013.01.009.

GRAFFITHS, M. J.; HARRISON, S. T. L. Lipid productivity as a key characteristic for choosing algal species for biodiesel production. Journal of Applied Phycology, v. 21, p. 493-507, 2009. Disponível em: <http://link.springer.com/article/10.1007/ s10811-008-9392-7>. Acesso em: 06 abr. 2014. DOI 10.1007/ s10811-008-9392-7.

KLAUSMEIER, C. A. et al. Optimal nitroegn-to-phosphorus stoichiometry of phytoplankton. Nature, v. 429, p. 171-174, 2004. Disponível em: <http://www.nature.com/nature/journal/ v429/n6988/full/nature02454.html>. Acesso em 07 abr. 2014. doi: $10.1038 /$ nature 02454 .

MENEZES, J. S. et al. Desalination of brackish water for household drinking water consumption using typical plants seeds of semi arid regions. Desalination, v. 281, p. 271-277, 2011. Disponível em: <http://www.sciencedirect.com/science/article/pii/ S0011916411006862>. Acesso em: 17 ago. 2012. DOI: 10.1016/j. desal.2011.08.002.

MORIOKA, L. R. I. et al. Floculação de Chlorella sp. produzida em concentrado de dessalinização e estudo de método de extração de lipídeos intracelulares, Química Nova, v. 37, n. 1, p. 44-49, 2014. Disponível em: <http://www.scielo.br/pdf/qn/v37n1/09. pdf $>$. Acesso em: 25 fev. 2014. http://dx.doi.org/10.1590/S010040422014000100009 .

PARK, J. B. K. et al. Wastewater treatment high rate algal ponds for biofuel production. Bioresource Technology, v. 102, p. 3542, 2011. Disponível em: <http://www.sciencedirect.com/science/ article/pii/S0960852410011636>. Acesso em: 22 set. 2012. DOI: 10.1016/j.biortech.2010.06.158. 
PEREZ-GARCIA, O. et al. Heterotrophic cultures of microalgae: Metabolism and potential products. Water Research, v. 45, p. 1136, 2011. Disponível em: <http://www.sciencedirect.com/science/ article/pii/S0043135410006019>. Acesso em: 21 ago. 2012. DOI: $10.1016 /$ j.watres.2010.08.037.

PITTMAN, J. K. et al. The potential of sustainable algal biofuel production using wastewater resources, Bioresource Technology, v. 102, p. 17-25, 2011. Disponível em: <http://www.sciencedirect.
com/science/article/pii/S0960852410010163>. Acesso em: 22 set. 2012. DOI: 10.1016/j.biortech.2010.06.035.

REDFIELD, A. C. The biological control of chemical factors in the environment. American Scientist, v. 46, n. 3, p. 205-221, 1958.

SUASSUNA, J. Potencialidades hídricas do nordeste brasileiro. Parcerias Estratégicas, v. 20, p. 119-144, 2005. Disponível em: $<$ http://www.cgee.org.br/arquivos/p_20_1.pdf $>$. Acesso em: 22 nov. 2010. 